\title{
A taxonomic study on rainy season weeds in Maitha block of Kanpur dehat district
}

\section{NIKHIL AGNIHOTRI}

Article Chronicle :

Received:

29.12.2015;

Revised :

16.04.2016;

Accepted :

30.04.2016
ABSTRACT : Weeds are self-grown unwanted plants which grow out of place and time. Presence of weeds creates many problems like decreased crop production, reduced crop quality, loss of animal products, loss of animal health, harmful effect on human health, adverse effect on industrial areas, aquatic ecosystem etc. They are self-grown plants which occur in gardens, fields, agricultural lands, roadsides, moist and water logged places especially in rainy season. Present study is based on taxonomic enumeration of rainy season weeds of Maitha block of Kanpur Dehat district. A total of 56 rainy season weeds belonging 50 genra of 30 families were identified and analyzed with their botanical names, families, local (Hindi) and English names, habits and habitats etc.

HOW TO CITE THIS ARTICLE : Agnihotri, Nikhil (2016). A taxonomic study on rainy season weeds in Maitha block of Kanpur dehat district. Asian J. Environ. Sci.,11(1): 30-33, DOI: 10.15740/HAS/AJES/11.1/30-33.

Key Words : Weeds, Taxonomic studies, Kanpur Dehat, Self-grown Plants 